\title{
Thrombus or plaque? The ultrasound as a diagnostic orientation tool in a primary care centre
}

\author{
Manuel Frías Vargas ${ }^{1 *}$, Beatriz López Uriarte ${ }^{2}$, Oscar H Franco ${ }^{3}$ and Vicente Pallarés Carratalá ${ }^{4}$ \\ ${ }^{1}$ Comillas Primary Care Centre, Madrid. Spain \\ ${ }^{2}$ Humanes Primary Care Centre, Madrid. Spain \\ ${ }^{3}$ University of Bern. Institute of Social and Preventive Medicine (ISPM), Bern, Switzerland \\ ${ }^{4}$ Department of Medicine, Universitat Jaume I, Health Surveillance Unit. Unión de Mutuas. Castellón. Spain
}

\begin{abstract}
We present a clinical case that shows a 73-year-old male diagnosed with plaque in the right internal carotid artery, the result of computerized axial tomography by an extension study of squamouscell carcinoma, shows a mural thrombosis. Ultrasound is performed in Primary Care shows a plaque that echographically looks like a thrombus and is referred to the vascular surgery service for study.
\end{abstract}

\section{Case report}

A 73-year-old male with a personal history of right and nasal facial epidermoid carcinoma, operated in 2016 and dyslipidemia in treatment under control with no other vascular risk factors in treatment with simvastatin $20 \mathrm{mg} /$ day. No history of cardiovascular events or coagulation disorders.

This patient came to our clinic with the results of computerized axial tomography (CAT) with neck contrast for the extension study of facial epidermoid carcinoma ordered by the otorhinolaryngology department (OD). The results of the CAT: "Mural thrombosis in the carotid bulb with extension to the right internal carotid artery and stenosis of 65\%". We decide to start antiagregation (acetylsalicylic acid $100 \mathrm{mg} /$ day) treatment and statins (atorvastatin $40 \mathrm{mg} /$ day), furthermore the patients sent to the department of vascular surgey (VS). In the physical examination the patient was conscious, blood pressure: $130 / 80 \mathrm{mmHg}$ and heart rhythm of 90 beats per minute. Pulmonary auscultation: regular heart sounds, conserved vesicular murmur. No murmurs are heard in the abdominal region and there weren't any neurological abnormalities. Ultrasound is performed in our primary care centre (PCC) finding plaque in the right internal carotid [1-3]: Hypoechogenic, heterogeneous and calcified (posterior shadow) that echographically looks like a thrombus. (Figure 1). Following this finding we communicated with the reference department of VS and the patient is sent for we supraortic trunks ultrasound, which confirms the finding of the ultrasound performed at the PC. The angio-CT is reported as an atheroma plaque in the internal carotid artery that causes a $70 \%$ stenosis (Figure 2). Cerebral and aortoiliac CT scans are performed, without finding any alterations. The patient is treated with high intensity statin (atorvastatin $80 \mathrm{mg} /$ day and antiagregation (acetylsalicylic acid $100 \mathrm{mg} /$ day).

\section{Clinical diagnosis}

Stenotic plaque in right internal carotid artery.

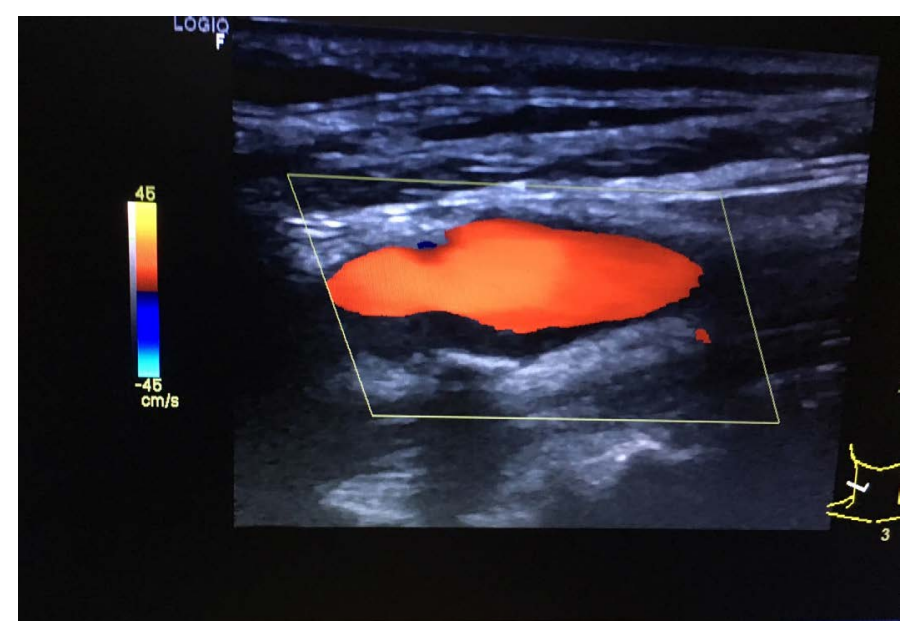

Figure 1. Ultrasound image of hypoechoic, heterogeneous and calcified plaque (posterior shadow) in right internal carotid that echographically looks like a thrombus.

\section{Differential diagnosis}

Mural thrombus.

\section{Comments}

The implementation of ultrasound in primary care can serve as an instrument for diagnostic guidance. In this case, using the ultrasound allowed us to guide the diagnosis and monitoring of an incidental finding in CT scan performed in hospital care. This permitted our

${ }^{\star}$ Correspondence to: Manuel Frías Vargas, Comillas Primary Care Centre, Madrid. Spain, E-mail: drfrias_v@hotmail.com

Received: June 08, 2018; Accepted: June 19, 2018; Published: June 22, 2018 


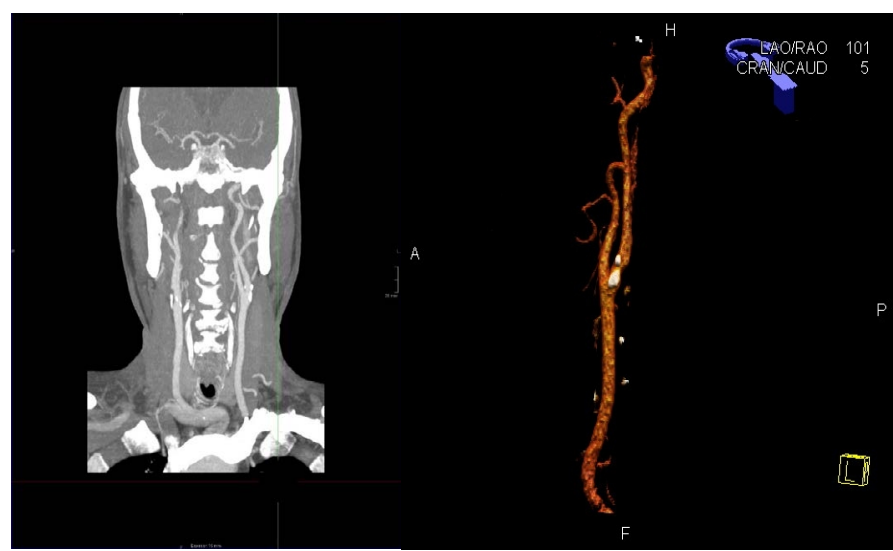

Figure 2. Angio-CT image of atheromatous plaque in the right internal carotid that causes a $70 \%$ stenosis. primary care practice to forward the patient for vascular surgery evaluation and treatment in a prompt manner.

\section{References}

1. Vlachopoulos C, Xaplanteris P, Aboyans V, Brodmann M, Cífková R, et al. (2015) The role of vascular biomarkers for primary and secondary prevention. A position paper from the European Society of Cardiology Working Group on peripheral circulation Endorsed by the Association for Research into Arterial Structure and Physiology (ARTERY) Society. Atherosclerosis 241: 507-532. [Crossref]

2. Catapano AL, Graham I, De Backer G, Wiklund O, Chapman MJ, et al. (2016) 2016 ESC/EAS Guidelines for the Management of Dyslipidaemias. Atherosclerosis 253: 281-344. [Crossref]

3. Frías Vargas M, Díaz Rodríguez N, Vidal Sánchez A, Carrasco Carrasco E, Rodríguez González J, et al. (2015) Manual vascular clínico-ecográfico en Atención Primaria: Manual de herramientas no invasivas-ecográficas-doppler en Atención Primaria para búsqueda de arteriosclerosis subclínica, GT ecografía y Vasculopatías de SEMERGEN: Editora Anna Formación, 2015.

Copyright: $\odot 2018$ Vargas MF. This is an open-access article distributed under the terms of the Creative Commons Attribution License, which permits unrestricted use, distribution, and reproduction in any medium, provided the original author and source are credited. 